\title{
Analysis of furans and pyridines from new generation heated tobacco product in Japan
}

Kanae Bekki* ${ }^{*}$, Shigehisa Uchiyama, Yohei Inaba and Akira Ushiyama

\begin{abstract}
Background: In recent years, heated tobacco products (HTPs), which are widely used in Japan, have been sold by various brands using additives such as flavors. It has been reported that the components of mainstream smoke are different from those of conventional cigarettes. In this study, we established an analytical method for furans and pyridines in the mainstream smoke, which are characteristic of HTPs and particularly harmful among the generated components, and investigated the amount of component to which the smokers are exposed.
\end{abstract}

Methods: We established a simple analytical method for simultaneous analysis of gaseous and particulate compounds in the mainstream smoke of HTPs (IQOS, glo, ploom S) in Japan by combining a sorbent cartridge and glass fiber filter (Cambridge filter pad (CFP)). Both the sorbent cartridge and CFP were extracted using 2-propanol and analyzed via GC-MS/MS to determine the concentration of furans and pyridines generated from each HTP.

Results: The results showed that the levels of target furans such as furfural, 2-furanmethanol, 2(5H)-furanone, and 5methylfurfural tended to be higher in the mainstream smoke of glo than in standard cigarettes (3R4F). Pyridine, which is generated at a high level in 3R4F as a combustion component, and 4-ethenylpyridine (EP), which is a known marker of environmental tobacco smoke, were detected. Among these components, 2-furanmethanol and pyridine are classified as Group 2B (possibly carcinogenic to humans) by the International Agency for Research on Cancer (IARC). Therefore, it is possible that they will contribute to the health effects caused by use of HTPS.

Conclusions: Using the new collection and analytical method for furans and pyridines in the mainstream smoke of HTPs, the level of each compound to which smokers are exposed could be clarified. By comprehensively combining information on the amount of ingredients and toxicity, it will be possible to perform a more detailed calculation of the health risks of using HTPs. In addition, the components detected in this study may be the causative substances of indoor pollution through exhaled smoke and sidestream smoke; therefore, environmental research on the chemicals generated from HTPs would be warranted in future studies.

Keywords: Heated tobacco product, Pyridines, Furans, Sorbent cartridge

\footnotetext{
* Correspondence: bekki.k.aa@niph.go.jp

Department of Environmental Health, National Institute of Public Health,

2-3-6 Minami, Wako, Saitama 351-0197, Japan
}

(C) The Author(s). 2021 Open Access This article is licensed under a Creative Commons Attribution 4.0 International License, which permits use, sharing, adaptation, distribution and reproduction in any medium or format, as long as you give appropriate credit to the original author(s) and the source, provide a link to the Creative Commons licence, and indicate if changes were made. The images or other third party material in this article are included in the article's Creative Commons licence, unless indicated otherwise in a credit line to the material. If material is not included in the article's Creative Commons licence and your intended use is not permitted by statutory regulation or exceeds the permitted use, you will need to obtain permission directly from the copyright holder. To view a copy of this licence, visit http://creativecommons.org/licenses/by/4.0/ The Creative Commons Public Domain Dedication waiver (http://creativecommons.org/publicdomain/zero/1.0/) applies to the data made available in this article, unless otherwise stated in a credit line to the data. 


\section{Background}

In recent years, much interest has been focused on new types of cigarettes, such as heated tobacco products (HTPs), which are widely used in Japan. The main feature of this new type of cigarette is the reduced content of harmful compounds compared to that in other conventional cigarettes. However, as these products are available on the market, there are few epidemiological data on carcinogenicity, genotoxicity, and the like, and many unknown problems remain regarding toxicity and safety. In fact, carcinogenic compounds such as tobaccospecific nitrosamines (TSNAs) [1] and carbonyl compounds [2], which are regulated by WHO, have been detected in the mainstream smoke of HTPs so far. The concentration of these compounds was significantly reduced compared to that in cigarettes. Although the concentration of these hazardous compounds is very low, smokers are at risk of direct exposure to these substances and face health risks. Furthermore, among the components detected in the mainstream smoke of HTPs, those with a concentration similar or higher than that in cigarettes have also been detected [3].

Among these detected components, additives such as flavors and compounds generated due to heating of the additives tend to be detected at relatively high concentrations compared to other combustion materials. In general, most of the additives used as flavors in tobacco products are safe as food additives, but the American Food Fragrance Manufacturers Association (FEMA) has pointed out that some of these food additives are of concern for safety (1037 types) [4]. In addition, among the detected components, furans including $2(5 \mathrm{H})$-furanone and 2-furanmethanol, which are also detected in foods after thermal decomposition of sugars, and pyridines (e.g., 4-ethenylpyridine (4-EP), which is produced following thermal decomposition of nicotine), were also detected in the smoke of HTPs [3]. Among these components, 2-furanmethanol and pyridine are classified as Group 2B (possibly carcinogenic to humans) by the International Agency for Research on Cancer (IARC). In addition, 2(5H)-furanone has also been reported to have toxic effects such as cytotoxicity due to DNA fragmentation in in vitro studies [5], and benzyl alcohol, linalool, menthol, and eugenol have also been used for the purpose of flavor [3]. It has also been suggested that these components are related to respiratory diseases, and their toxicity mechanism has been reported to involve an agonist compound of TRP channel (TRPA1), which is an inducer of cytotoxicity [6]. Therefore, it is possible that various additives contribute to health risks. However, data on these compounds are very limited, and there are few data on domestic HTPs [3]. In this study, we established a simple analytical method for simultaneous analysis of gaseous and particulate compounds by combining a sorbent cartridge and CFP; the method is an individual method for the collection of furans and pyridines from the mainstream smoke of HTPs. Furthermore, we tried to determine the amount of components generated from each HTP and the levels of the components to which smokers are exposed to obtain basic data for investigating their effects on human health.

\section{Methods}

\section{Apparatus and reagents}

Gas chromatography (GC) coupled with a triple quadrupole mass spectrometer (GCMS-TQ8040, SHIMADZU) and HP-5MS (30 m $\times 0.25 \mathrm{~mm}$ i.d., $0.25 \mu \mathrm{m}$ ) (Agilent Technologies, CA, USA) were used to quantify furans, pyridines, and other additives in the mainstream smoke in this study. GC coupled with a thermal conductivity detector (TCD) and a packed column (Porapack Q2 m×3 m i.d., 80-100 mesh deactivated stainless, GL Sciences, Tokyo, Japan) was used to quantify water in the mainstream smoke in this study. Nicotine 97\%, n-hexane > 96\%, 2-propanol > 99.7\%, methanol (high-performance liquid chromatography [HPLC] grade) $>99.9 \%$, acetic acid $>$ 99.7\%, and 2,6-dimethylpyridine were purchased from FUJIFILM Wako Chemicals, Ltd. (Osaka, Japan). 2,5Dimethylpyrazine, 2(5H)-furanone, 5-methylfurfural, nicotine, acetonitrile, and ammonium acetate ( $\geq 99.99 \%)$ were purchased from Sigma-Aldrich Inc. (St. Louis, MO, USA). Pyridine, furfural, 2-furanmethanol, 2-ethenylpyridine (2-EP), 3-ethenylpyridine (3-EP), 4-ethenylpyridine (4EP), 3-ethyl pyridine, 2,3,5-trimethylpyrazine, benzyl alcohol, linalool, menthol, 5-hydroxy-2-methylpyridine, isoquinoline, eugenol, and 4-ethyl guaiacol were purchased from Tokyo Kasei Co., Ltd., (Tokyo, Japan). The water used for sample preparation and analysis was deionized, and it was further purified using a Milli-Q water system (Millipore Co., Bedford, MA, USA).

In this study, we used conventional combustion cigarettes (3R4F) from the University of Kentucky (Lexington, KY, USA), IQOS (regular and menthol) from Philip Morris International Inc. (NY, USA), glo (berry boost and dark fresh) from British American Tobacco (NC, USA), and ploom $\mathrm{S}$ from Japan Tobacco Inc. (Tokyo, Japan). According to the International Organization for Standardization (ISO) 3402, these cigarettes were used for measurement after being placed at $22^{\circ} \mathrm{C}$ and $60 \%$ humidity for 2 days [7].

\section{Method of sampling main stream smoke of HTPs}

For sampling of the gas phase and particle phase of mainstream smoke of HTPs, a sorbent cartridge and CFP were used. To prepare the sorbent cartridge, 150 mg of Tenax GR (GL Sciences, Tokyo, Japan) was packed in a Rezorian tube $(1 \mathrm{~mL})$, and the cartridge was washed with $10 \mathrm{~mL}$ of 2-propanol and dried with 
nitrogen gas at a flow rate of $1.0 \mathrm{~L} / \mathrm{min}$ for $5 \mathrm{~min}$. Mainstream smoke of conventional combustion cigarette was collected with this sorbent cartridge connected between tobacco product and CFP according to the intense regime described in the standard operating procedure (SOP) 01 [8] and Health Canada, official method T-115 [9]. Briefly, mainstream smoke was collected under the following conditions: $55 \mathrm{~mL}$ puff volume, $2 \mathrm{~s}$ puff duration, 30 s puff interval, and $100 \%$ blocking of the filter ventilation holes with Mylar adhesive tape. The puff number of $3 \mathrm{R} 4 \mathrm{~F}$ as a standard conventional combustion cigarette was nine times. In case of HTPs, we produced a puffing profile for the collection of mainstream smoke of HTPs from battery time conditions of HTPs as described below. The maximum number of smoking absorption was twelve times for one dedicated stick from the calculation of smoking interval based on the $\mathrm{HCI}$ method (30 s) and battery time of IQOS (6 min). When the number of puffs was calculated for glo and ploom $\mathrm{S}$ by the same method as IQOS, the number of puffs for IQOS was the largest. Therefore, in order to compare the concentrations of three types of HTPs in the mainstream smoke, the total number of puffs was set as twelve puffs. So far, no official law has been established regarding the smoking interval and amount of smoke absorbed for HTPs. Actually, it is possible that research on smoking behavior of smokers who use HTPs has not been sufficiently conducted. Therefore, it is necessary to consider it as a future issue. Furthermore, for volatile compounds, many of them pass through the CFP at the time of collection and are collected in the sorbent cartridge, but those collected in the CFP may be slightly volatile during the collection of mainstream smoke of HTPs. Therefore, we need to do quickly pretreatment after the sample collection.

\section{Analytical method}

Both the sorbent cartridge and CFP were extracted using $5 \mathrm{~mL}$ and $10 \mathrm{~mL}$ of 2-propanol, respectively, for $30 \mathrm{~min}$ using a rotary shaker at 120 cycles per min. After extraction, isoquinoline was added as an internal standard and analyzed via GC-MS/MS. The GC oven temperature program was $50{ }^{\circ} \mathrm{C}$ (held for $2 \mathrm{~min}$ ) and increased to $200{ }^{\circ} \mathrm{C}$ at $6{ }^{\circ} \mathrm{C} / \mathrm{min}$ and $310{ }^{\circ} \mathrm{C}$ (held for $3 \mathrm{~min}$ ) at $20{ }^{\circ} \mathrm{C} /$ $\mathrm{min}$. Splitless injections were carried out at an injector temperature of $280{ }^{\circ} \mathrm{C}$ and splitless time of $1 \mathrm{~min}$. Helium (99.99995\%) was used as the carrier gas at a flow rate of $1.3 \mathrm{~mL} / \mathrm{min}$ (pressure $75 \mathrm{kPa}$ ). Mass spectrometric ionization was performed in the electron impact (EI) mode at a voltage of $70 \mathrm{eV}$. The transfer line and ion source temperatures were set to $280{ }^{\circ} \mathrm{C}$ and $230{ }^{\circ} \mathrm{C}$, respectively. To identify suitable precursor ions, full scan monitoring was performed for all compounds at the first MS with a mass range of $m / z 50-500$. Argon (99.999\%) was used as the collision-induced dissociation (CID) gas. To determine suitable product ions, full product ion spectra of selected precursor ions were obtained, and the optimum collision energies were determined for each identified $\mathrm{m} / z$ transition. The most abundant and apparent ions were chosen as the targets for quantification. The peaks of each compound that showed a signal-tonoise ratio $(\mathrm{S} / \mathrm{N})$ of 3 in the sample were identified by comparing the retention times (within $0.1 \mathrm{~min}$ ) and the ratios (within 20\%) of the two selected reaction monitoring transitions in the sample with those of the standards.

For the analysis of tar, we referred to the previous report by Bekki et al. [1]. The amount of tar exhausted in the mainstream smoke was calculated by subtracting the amount of nicotine and water from the total particulate matter (TPM) collected by CFP.

\section{Results and discussion}

\section{Sample collection and pretreatment}

To examine the extraction conditions of the components collected in the sampler, the extraction efficiency was investigated using organic solvents with different polarities as follows (2-propanol < ethyl acetate < ethanol < methanol). Because the physical properties regarding the polarity of each component are different, the extraction efficiency may differ depending on the type of solvent. Figure 1 shows the chromatograms obtained for the four different types of solvents. The detection sensitivity was slightly different for each component and solvent, and most of the components were detected more sensitively by 2-propanol which has properties as a polar solvent because it has hydrogen bonding properties due to hydroxy groups, while it also has properties as a non-polar solvent because it also has an isopropyl group which is a hydrophobic group. Therefore, 2-propanol is considered to have comprehensive solubility even for components having different polarities, and we decided to use 2propanol as the extraction solvent.

To determine the recovery rate of the compounds collected in the Tenax GR cartridge and CFP, $5 \mu \mathrm{g}$ of 19 targeting compounds was added to this cartridge and dried with nitrogen gas for $5 \mathrm{~min}$ at a flow rate of $1 \mathrm{~L} /$ min. After adding $5 \mathrm{~mL}$ of 2-propanol, extraction was performed using a rotary shaker at 120 cycles per min for $30 \mathrm{~min}$. The eluate was analyzed using GC-MS/MS. The recovery rate of 2-propanol was in the range of 91$102 \%$ for the Tenax GR cartridge.

\section{Calibration curve, LOD, and LOQ}

To obtain the quality control protocol for the analysis of furans, pyridines, and other additives, calibration curves were generated from the ratios of the areas of the peaks of six known concentrations of standard and quinoline as an internal standard. The detection limit (LOD) and 

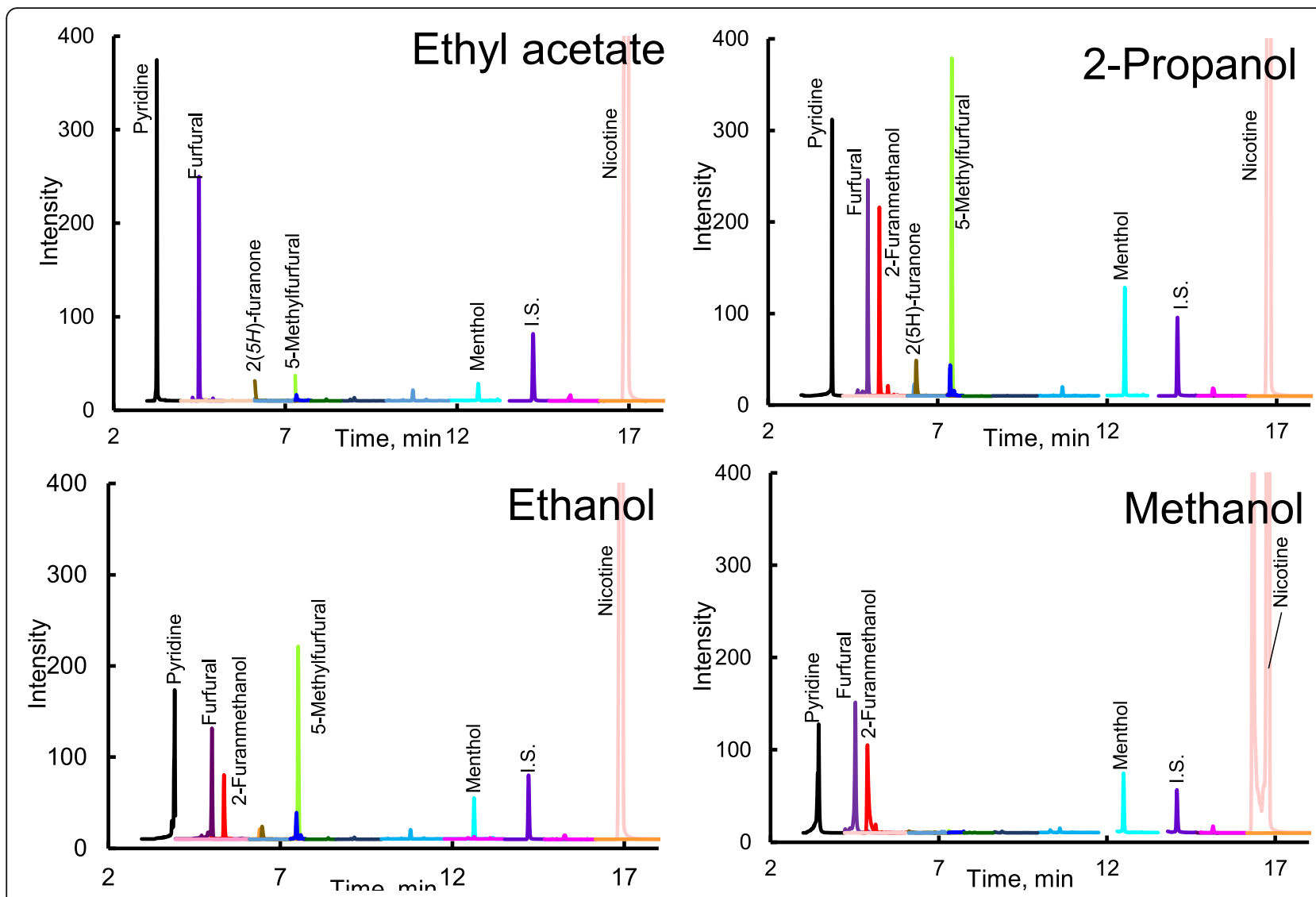

Fig. 1 MRM chromatograms of mainstream smoke of IQOS (regular) extracted with polar and non-polar solvent

quantification limit (LOQ) for the measurement of furans and pyridines were defined as three and ten times the standard deviation of the lowest standard, respectively. Each calibration curve showed good linearity $\left(r^{2}>\right.$ 0.9772 ) in the range of $0.005-0.2 \mu \mathrm{g} / \mathrm{mL}$ for 2,6 dimethylpyridine and $2(5 \mathrm{H})$-furanone; $0.01-0.5 \mathrm{ng} / \mathrm{mL}$ for 5-methylfurfural, pyridine, 2,5-dimethylpyrazine, and 2-EP; $0.002-0.5 \mathrm{ng} / \mathrm{mL}$ for 3-ethylpyridine; $0.01-1.0 \mu \mathrm{g} /$ $\mathrm{mL}$ for methanol and 4-ethyl guaiacol; $0.02-1.0 \mu \mathrm{g} / \mathrm{mL}$ for furfural, 3-EP, 4-EP, and 2,3,5-trimethylpyrazine; $0.5-50 \mu \mathrm{g} / \mathrm{mL}$ for 2-furanmethanol; and $0.05-1.0 \mu \mathrm{g} / \mathrm{mL}$ for nicotine, benzyl alcohol, and eugenol (Table S1).

\section{Concentrations of furans and pyridines in the mainstream smoke of HTPs}

Figure 2 shows an MRM chromatogram obtained from the analysis of furans, pyridines, and other target compounds from the mainstream smoke extract of IQOS (regular). At this time, 12 of the 19 target compounds were detected. These components in the mainstream smoke of HTPs mainly include components produced by heating and migrated from tobacco leaves. In addition, the concentration shown in Table 1 is the sum of the components detected using the sorbent cartridge and CFP.

Among the target components detected from IQOS, furans were detected at relatively high concentrations in the following order: furfural $>5$-methylfurfural $>2$ furanmethanol $>2(5 \mathrm{H})$-furanone, and pyridine was also detected at high concentration. And, almost of these components were detected in the gas phase collected by sorbent cartridge (Tables S3, S4, S5 and S6). These furans are often derived from flavors used for HTPs; however, conversely, they are also known as a product of heating reaction of sugars and amino acids contained in tobacco leaves, which is known as a Maillard reaction [10-12]. Furthermore, EP has generally been used as a gaseous marker of environmental tobacco smoke (ETS) derived from nicotine. Therefore, it was considered that the EP detected here could also be used as a marker component of the second- and third-hand smoke of HTPs $[13,14]$. In fact, some volatile compounds in the mainstream smoke of cigarettes and electronic cigarettes are emitted from the exhaled breath of smokers $[15,16]$. A few studies have also reported the sidestream emission of some volatile compounds, including EP [17]. Therefore, 

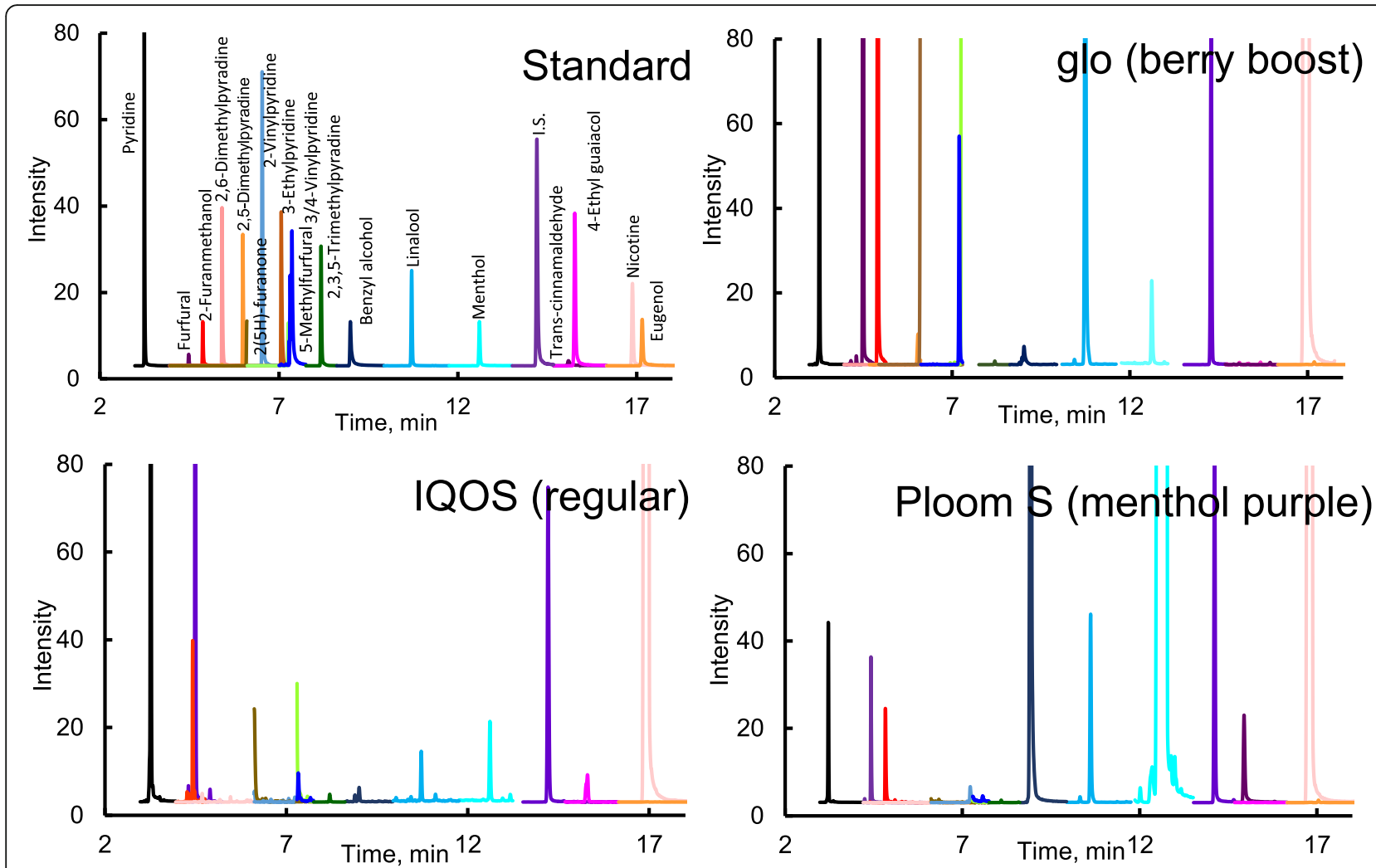

Fig. 2 MRM chromatograms of standard and mainstream smoke of HTPs (IQOS, glo, ploom S). The concentration of the standard mix was $0.5 \mu \mathrm{g} / \mathrm{mL}$

it is possible that EP will become an evaluation index for the effects of exhaled smoke and second- and third-hand smoke of HTPs in an indoor environment. However, EP cannot be used as an environmental marker only for HTPs because it is also affected by cigarettes.

In addition, the mainstream smoke of three types of HTPs (IQOS, glo, and ploom S) that are in high demand in Japan was compared in this study. As shown in Table 1 , similar to IQOS, relatively large amount of furans was detected, especially in glo and ploom $\mathrm{S}$. The reason for these results is that furans are widely used as fragrances (furfural, 5-methylfurfural, 2-furanmethanol) in HTPs. Therefore, it was presumed that relatively high concentrations would be detected in glo, which has many brands that use various flavors. In contrast, pyridine and nicotine were detected at relatively higher concentrations in IQOS than in glo and ploom S, although these concentrations were significantly lower than the cigarette $(3 \mathrm{R} 4 \mathrm{~F})$ burned at around $800{ }^{\circ} \mathrm{C}$. The reason for these results was speculated to be the difference in the heating temperature of each product: IQOS $\left(350{ }^{\circ} \mathrm{C}\right)$ $>$ glo $\left(240{ }^{\circ} \mathrm{C}\right)>$ ploom $\mathrm{S}\left(200{ }^{\circ} \mathrm{C}\right)$. Furthermore, the principle of each HTPs is very different. Actually, IQOS use a stick containing tobacco leaves which is inserted into a holder and heated from the inside with a heating blade. On the other hand, glo and ploom S use a stick containing tobacco leaves inserted into a holder and heated from the surroundings. These characteristics also may affect the difference of concentrations of each compound detected in the mainstream smoke of HTPs.

\section{Amount of target compounds detected in the mainstream smoke of HTPs with the puff numbers}

Figure 3 shows the concentration of furans and pyridines in mainstream smoke generated from IQOS (regular) using a sorbent cartridge for each puff. In this figure, the amount of component collected from each puff is indicated with a white marker, and the value accumulated up to 12 puffs is indicated with a black marker. From these results, it was confirmed that most of the compounds increased depending on the number of puffs. However, 2-furanmethanol was below the detection limit up to the second puff, and it seemed that it would take time from heating to generation. In addition, in this study, three heat sticks were used for the collection and quantification of compounds emitted from the mainstream smoke of HTPs in one sorbent cartridge. However, the results of this experiment showed that it was possible to quantify the components in mainstream smoke by the number of puffs or by one heat stick. In 


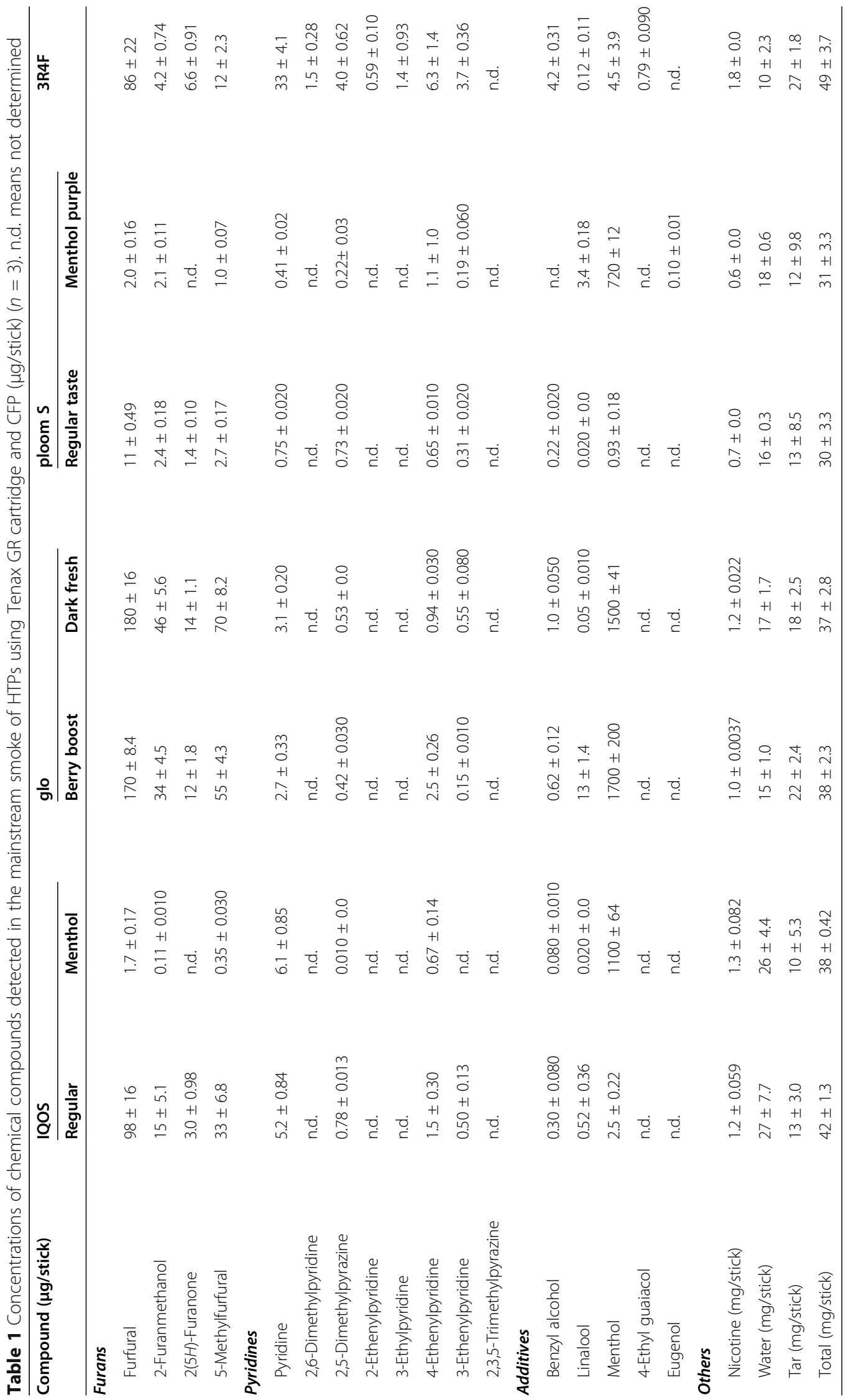



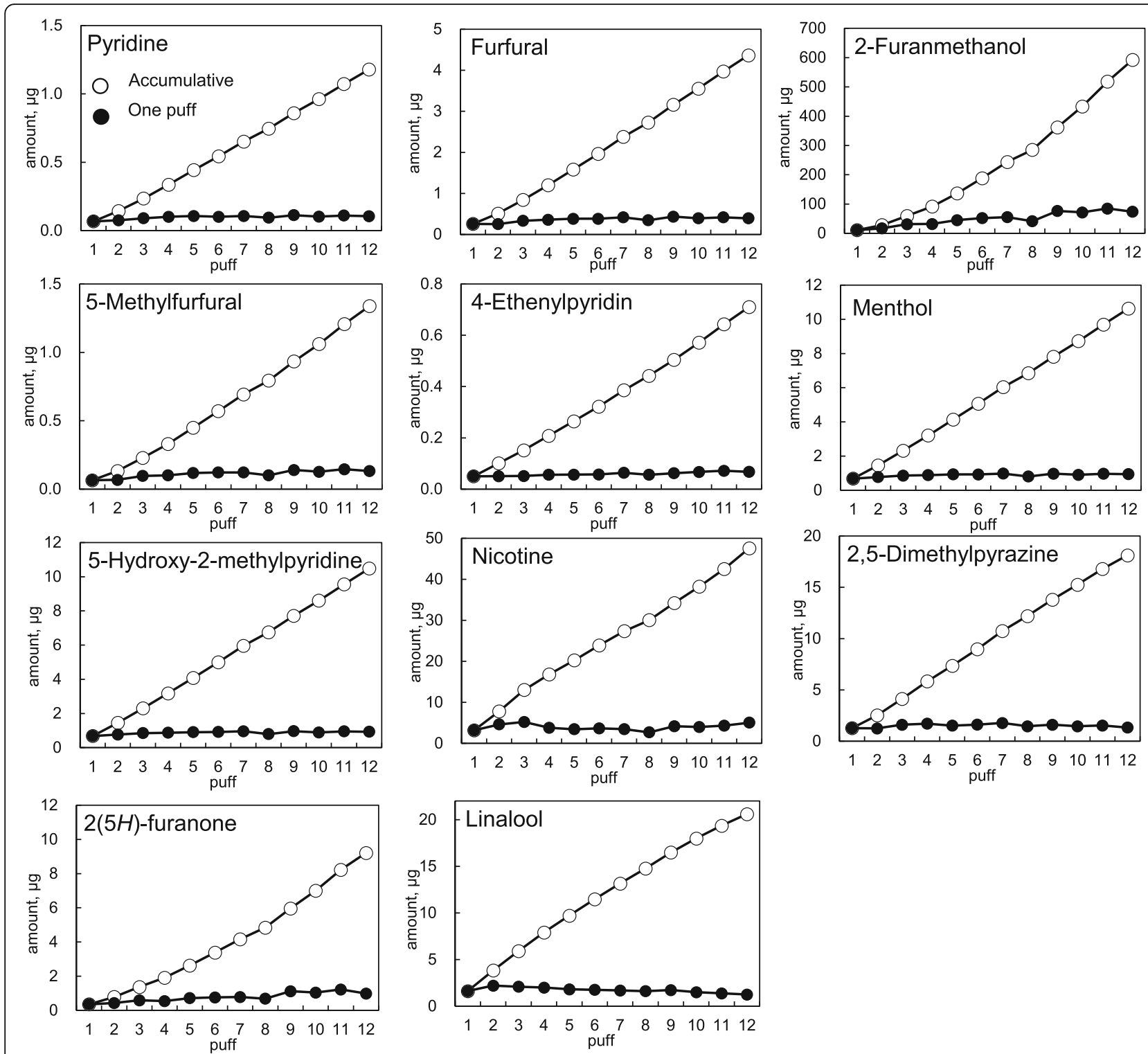

Fig. 3 Changes in the amount of target compounds detected in the mainstream smoke of IQOS (regular)

fact, the official law regarding the smoking method of HTPs has not been established because the smoking behavior of smokers who use HTPs has not been clarified. Therefore, it is also possible to collect and quantify the mainstream smoke suitable for the smoking behavior of HTPs.

\section{Conclusions}

By using the sorbent cartridge and CFP for the collection and analysis of furans and pyridines in the mainstream smoke of HTPs, the level of each compound to which smokers are exposed could be determined. By comprehensively combining information on the amount of ingredients and toxicity, it will be possible to perform a more detailed calculation of health risks compared to that performed before. Furthermore, in recent years, the effects of indoor pollution and second-hand smoke caused by HTPs have been reported. Therefore, the compounds detected at relatively high concentrations of HTPs in this study may be used as indicators of secondand third-hand smoke in the future studies.

\section{Abbreviations}

CFP: Cambridge filter pad; CID gas: Collision-induced dissociation gas; El: Electron impact; 3-EP: 3-Ethenylpyridine; 4-EP: 4-Ethenylpyridine;

FEMA: American Food Fragrance Manufacturers Association; GC-MS/MS: Gas chromatography coupled with triple quadrupole mass spectrometer; GC-

TCD: Gas chromatography coupled with a thermal conductivity detector; HTPs: Heated tobacco products; HPLC: High-performance liquid chromatography; IARC: International Agency for Research on Cancer; ISO: International Organization for Standardization; LOD: Detection limit; LOQ: Quantification limit; SOP: Standard operating procedure;

TSNAs: Tobacco-specific nitrosamines 


\section{Supplementary Information}

The online version contains supplementary material available at https://doi. org/10.1186/s12199-021-01008-1.

Additional file 1: Supplementary data. Supplementary data associated with this article can be found in the table S1, S2. Table S1. Calibration curves, detection limits, and quantification limits for the chemical compounds. Table S2. MS/MS parameters for the target compounds. Table S3. Concentrations of chemical compounds detected in the mainstream smoke of IQOS using Tenax GR cartridge and CFP ( $\mu \mathrm{g}$ / stick) $(n=3)$. n.d. means not determined. Table S4. Concentrations of chemical compounds detected in the mainstream smoke of glo using Tenax GR cartridge and CFP ( $\mu \mathrm{g} / \mathrm{stick})(n=3)$. n.d. means not determined. Table S5. Concentrations of chemical compounds detected in the mainstream smoke of ploom S using Tenax GR cartridge and CFP ( $\mu \mathrm{g}$ / stick) $(n=3)$. n.d. means not determined.

\section{Acknowledgements}

The authors thank Ms. Yoko Kishiro of the National Institute of Public Health, Japan, for the technical support. We would like to thank Editage (www. editage.com) for the English language editing.

\section{Authors' contributions}

K.B. carried out the experiment and wrote the manuscript with support from S.U.. A.U. and Y.I. helped supervise the project. All authors discussed the results and commented on the manuscript. The authors read and approved the final manuscript.

\section{Funding}

This work was supported by the Health and Labour Science Research Grants from the Ministry of Health, Labour and Welfare of the Japanese Government.

Availability of data and materials

Please contact the author for data requests.

\section{Declarations}

Ethics approval and consent to participate

Not applicable

\section{Competing interests}

The authors declare that they have no competing interests.

Received: 23 February 2021 Accepted: 21 August 2021

Published online: 13 September 2021

\section{References}

1. Bekki K, Inaba Y, Uchiyama S, Kunugita N. Comparison of chemicals in mainstream smoke in heat-not-burn tobacco and combustion cigarettes. J UOEH. 2017:39:201-7.

2. Uchiyama S, Noguchi M, Takagi N, Hayashida H, Inaba Y, Ogura H, et al. simple determination of gaseous and particulate compounds generated from heated tobacco products. Chem Res Toxicol. 2018;31:585-93.

3. St Helen G, Jacob lii P, Nardone N, Benowitz NL. IQOS: examination of Philip Morris International's claim of reduced exposure. Tob Control. 2018;1:s30-6.

4. Alert N. Preventing lung disease in workers who use or make flavorings: NIOSH Publication; 2003. No. 2004-2110

5. Calderón-Montano JM, Burgos-Moróna E, Orta ML, Pastor N, Austin CA, Mateos S, et al. Alpha, beta-unsaturated lactones 2-furanone and 2-pyrone induce cellular DNA damage, formation of topoisomerase I- and II-DNA complexes and cancer cell death. Toxicol Lett. 2013;222:64-71.

6. Kaur G, Muthumalage T, Rahman I. Mechanisms of toxicity and biomarkers of flavoring and flavor enhancing chemicals in emerging tobacco and nontobacco products. Toxicol Lett. 2018;15:143-55.

7. International Organization for Standardization (ISO). Tobacco and tobacco products-atmosphere for conditioning and testing. ISO 3402. Geneva; 1999. p 1-3.

8. World Health Organization (WHO) (2012): Standard operating procedure for intense smoking of cigarettes.
9. Health Canada. Determination of tar, nicotine and carbon monoxide in mainstream tobacco smoke. Official method T-115. Ottawa: 1999. p 1-6.

10. Kaimoto T, Hatakeyama Y, Takahashi K, Imagawa T, Tominaga M, Ohta T. Involvement of transient receptor potential A1 channel in algesic and analgesic actions of the organic compound limonene. Eur J Pain. 2016;20: 1155-65.

11. Hodge JE. Dehydrated foods, chemistry of browning reactions in model systems. J Agric Food Chem. 1953;1:928-43.

12. Sleiman M, Logue JM, Luo W, Pankow JF, Gundel LA, Destaillats H. Inhalable constituents of thirdhand tobacco smoke: chemical characterization and health impact considerations. Environ Sci Technol. 2014;48:13093-101.

13. Hyvärinen MJ, Rothberg M, Kähkönen E, Mielo T, Reijula K. Nicotine and 3ethenylpyridine concentrations as markers for environmental tobacco smoke in restaurants. Indoor Air. 2000;10:121-5.

14. Kuusimäki L, Peltonen K, Vainiotalo S. Assessment of environmental tobacco smoke exposure of Finnish restaurant workers, using 3-ethenylpyridine as marker. Indoor Air. 2007;17:394-403.

15. Capone S, Tufariello M, Forleo A, Longo V, Giampetruzzi L, Radogna AV, et al. Chromatographic analysis of VOC patterns in exhaled breath from smokers and nonsmokers. Biomed Chromatogr. 2018;32:e4132.

16. Van Drooge BL, Marco E, Perez N, Grimalt JO. Influence of electronic cigarette vaping on the composition of indoor organic pollutants, particles, and exhaled breath of bystanders. Environ Sci Pollut Res Int. 2019;26:4654-66.

17. Ruprecht AA, De Marco C, Saffari A, Pozzi P, Mazza R, Veronese C, et al. Environmental pollution and emission factors of electronic cigarettes, heatnot-burn tobacco products, and conventional cigarettes. Aerosol Sci. Technol. 2017:51:674-84.

\section{Publisher's Note}

Springer Nature remains neutral with regard to jurisdictional claims in published maps and institutional affiliations.
Ready to submit your research? Choose BMC and benefit from:

- fast, convenient online submission

- thorough peer review by experienced researchers in your field

- rapid publication on acceptance

- support for research data, including large and complex data types

- gold Open Access which fosters wider collaboration and increased citations

- maximum visibility for your research: over $100 \mathrm{M}$ website views per year

At $\mathrm{BMC}$, research is always in progress.

Learn more biomedcentral.com/submissions 